\title{
COVID-19 PANDEMIC ENCOURAGES TO DEEPEN THE STUDY OF THE THYROID GLAND: CORRELATION PORTRAITS AS A MEANS OF RESEARCH IN DIFFERENT DIRECTIONS OF FOLLICULAR THYROCYTES ACTIVITIES
}

Olha Ryabukha ${ }^{1}$ (PhD in Medical Sciences, Associate Professor)

${ }^{1}$ Lviv Medical Institute LLC, Lviv, Ukraine

*Corresponding author: Olha Ryabukha

Abstract. In COVID-19, the thyroid gland can play a significant role both in the clinical course of the disease and in the processes of postcovid recovery. Based on the importance of the thyroid gland for the vital functions of the body, information on the etiology of the most common types of thyroid pathology is considered. It is established that the disclosure of the deep essence of the
Received: January 22, 2022

Published: February 01, 2022

processes occurring in the thyroid gland in normal and pathology is possible on the basis of innovative use of correlation analysis with the designing of correlation portraits to study the main activities of follicular thyrocytes.

Keywords: COVID-19, thyroid gland, hypothyroidism, hyperthyroidism, mathematical methods of thyroid research.

Introduction. Coronavirus infection, which has now spread around the world, is characterized by rapid spread and general severe consequences for the body. The first WHO notification on the danger of a disease caused by the coronavirus SARSCov-2 (Severe Acute Respiratory Syndrome Coronavirus 2) and named COVID-19 (Coronavirus Disease 2019), dated 31.12.2019. As early as January 30, 2020, the WHO declared that the outbreak was a global health emergency, and from March 21, 2020, the global pandemic COVID-19 was reported. The constantly updated monitoring site "Worldometer" reports that as of January 20, 2022, 339,853946 million people in the world have been confirmed to be infected with COVID-19, and 5,585826 million people have been diagnosed with deaths from this disease [1]. Therefore, the identification of factors that cause severe COVID-19 is important for risk stratification 
and can help optimize treatment, establish recommendations and measures in the field of health care $[2,3]$.

Coronaviruses as pathogens of the infectious process can affect the vast majority of organs. According to autopsies of people who died from COVID-19, pathological changes in the body are characterized by considerable diversity [4]. Thus, in the lungs, which are considered the main target of SARS-Cov-2 virus, there are diffuse alveolar lesions against the background of small arteries thrombosis, acute alveolitis combined with thrombovasculitis, pulmonary infarction $[5,6]$. Another target organ is the kidney [7], which affects functionally important elements - Bowman's capsule and the epithelium of the proximal tubules, described are cases of damage to the capillaries of the glomeruli. In the myocardium [8] there is an acute myocardial infarction, myocarditis, cardiomyopathy, death of cardiomyocytes, in skeletal muscle impairment or absence of rhabdomyocytes' specific striation and focal necrosis of their cytoplasm. In 14-53\% of autopsies [4], apoptosis processes are activated in the liver tissue. Thus, we can note that the main pathomorphological manifestations of coronavirus lesions in these organs are such general pathological processes as circulatory disorders, dystrophy, necrosis, inflammation. At the same time, the interaction of the virus with the thyroid gland has certain features. Thus, the complex interaction of SARS-Cov-2 and thyroid gland is indicated by [9], who note that when thyroid follicles are damaged by SARS-Cov-2 virus, no morphological signs of necrosis and lymphocytic infiltration are observed: desquamation of follicular epithelium with its loss in the cavity of the follicles, which lose colloid, eventually leads to their destruction against the background of the parafollicular cells defeat [10]. Instead, [11] indicate that the associated inflammatory reactions have certain features. Mechanism of the immune response when the virus comes into contact with thyroid gland cells lies in the formation of complex aggregates [12], at this the important pathogenetic factors of influence are Transmembrane serine protease 2 (TMPRSS2), which is required for activation of SARS-Cov-2 virus protein, and AngiotensinConverting Enzyme 2 (ACE2), which is a receptor for the virus that enters thyrocytes and reproduces there [13]. The level of ACE2 expression in the thyroid gland is higher 
than in the lung tissue [14]. This turns the thyroid gland into a potential target for the virus.

Against the background of reports on the possibility of provoking the development of atypical subacute thyroiditis (de Quervain thyroiditis) and Graves' disease $[10,15]$, there is a good opinion that pathological changes in the thyroid gland may be signs of direct action of the virus. The course of such changes and their consequences can be largely determined by the state of the thyroid gland itself, as it plays a leading role in all types of metabolism, growth processes and differentiation of tissues [16]. In addition, the thyroid gland is an important part of the regulatory systems "hypothalamus - pituitary - thyroid", "thyroid - adrenal glands", "thyroid - gonads" $[17,18]$. The fact that thyroid hormones are crucial for the body, is indicated by the presence of cellular receptors to them in almost all tissues and organs [19]. In the case of the COVID-19 pandemic, studies and in-depth analysis of morpho-functional features of the thyroid gland in normal and pathology requires close attention and the development of new approaches.

The ideas about the causes and mechanisms of thyroid pathology are changing as new information accumulates: the etiopathogenesis of some thyroid diseases has been clarified, supplemented or revised. Although the thyroid gland is very sensitive to a variety of adverse environmental effects [20], the predominant share of thyroid pathology are conditions caused by iodine deficiency in the environment. The term "iodine deficiency disease" is used to denote them [21]. The range of their clinical manifestations and consequences for the body depend on many factors, in particular, the age at which the body suffers from iodine deficiency, the degree of iodine deficiency, micro- and macronutrient status of the habitat. Thus, local thyroid damage is not the main consequence of iodine deficiency pathology - all body systems are involved in the pathological process.

Prevention of iodine deficiency and diseases is carried out by additional iodine intake [22,23]. Currently, inorganic iodine-containing compounds are used for this purpose: mainly potassium iodate, less often potassium iodide. As an alternative to inorganic iodine, the possibility of using its organic compounds is being studied. The 
use of seaweed is considered to be especially promising - it has been proven that they activate metabolic processes, intensify the synthetic activity of thyrocytes, improve the general condition of the body [24]. One of such plants is kelp Laminaria the therapeutic effect of which is due to the high content of iodine [25]. Iodine-protein components from the Black Sea red alga Phyllophora crispa (Phyllophora nervosa) has a high ability to enhance the synthetic activity of the thyroid gland in conditions of alimentary iodine deficiency [26,27]. However, the question of the priority use of inorganic or organic iodine for prevention or correction of iodine deficiency remains unresolved. We believe that significant progress in its solution can be achieved using mathematical methods [28,29], as the involvement of mathematics as a research tool can significantly expand and enrich the researcher's ability to study changes in thyroid cells under the influence of iodine of different chemical nature in different conditions of observation. Thus, the peculiarities of thyroid function in modern conditions (interaction with SARS-Cov-2 in the pandemic of COVID-19, the effects of anthropogenic activities, nutritional deficiencies, etc.) require in-depth study.

The aim of the study was a theoretical study of thyroid gland's importance for the coordinated functioning of the body in the conditions of permissive and obligate thyroid pathology and substantiation of practical application of our mathematical approach to studying the main activities of follicular thyrocytes.

Materials and methods. The theoretical part of the study was carried out using bibliographic databases Google Scholar and Scopus using keywords in Ukrainian, English and Russian: thyroid, hypothyroidism, hyperthyroidism, thyroiditis, follicular thyrocyte, organic iodine, inorganic iodine, SARS-CoV-2, COVID-19, mathematical methods in medicine, correlation analysis, correlation portrait. The obtained data were collected and analyzed in order to answer questions about the interaction of SARSCoV-2 with thyrocytes in COVID-19, the importance of thyroid hormones for the body, the use of organic and inorganic iodine in prevention of iodine deficiency, the use of mathematical methods in medical studies. The practical part of the study was carried out based on the author's approaches to the study of synthetic, secretory, 
transport and energy activities directions of the thyroid gland's follicular thyrocytes by means of correlation analysis with the designing of correlation portraits.

The study of the article is a fragment of research work of LLC "Lviv Medical Institute" on "Improving the circulation of drugs during pharmacotherapy on the basis of evidence-based and forensic pharmacy, organization, technology, biopharmacy and pharmaceutical law" (state registration number 0120U105348, terms 2021-2026).

Results and discussion. Any task of medical diagnosis can be considered as a search for equation:

$$
X^{*}=\left(x_{1}^{*}, x_{2}^{*}, x_{3}^{*}, \ldots, x_{n}^{*}\right) \rightarrow d_{j} \in D=\left(d_{1}, d_{2}, d_{3}, \ldots, d_{m}\right),
$$

where $X^{*}$ is the set of parameters of the studied biological system's/organ's/patient's state, and $D$ is the set of states/diagnoses inherent in this field of medicine.

The difficulty of establishing such dependencies is due not only to the huge number of such parameters, but also due to their heterogeneous nature, as they can be quantitative (age, morphometric characteristics, content of certain substances, etc.), qualitative (nature, intensity and location of pain, emotional sensations, etc.) or binary (presence or absence of a state or process). The following mathematical methods are the most common in solving medical diagnostics: Bayesian analysis, regression analysis, logical programming (Prolog), programming on the basis of fuzzy set theory (Fuzzy logic), phase interval method, etc. [30]. However, they are poorly adapted or not adapted at all to work with qualitative (non-numerical) and binary databases - the inability to take them into account significantly complicates the diagnostic process. At the same time, in medicine, careful analysis of qualitative information, which is mostly heuristic and presented in linguistic form, is very important for proper diagnosis. The basis of mathematical processing of non-numerical (linguistic) information is the theory of fuzzy sets [31]. Unlike traditional models, which are based on the principles of quantitative mathematics, the adequacy of fuzzy logical statements does not change under slight fluctuations in experimental conditions. At the same time, diagnosing on the basis of fuzzy set theory presupposes the presence of rather rigid determinism, 
which is quite difficult to achieve in biological systems that are in a state of adaptation to any influences.

The most complete assessment of the thyroid gland's state, to carry out differential diagnosis, to develop effective scientifically sound pharmacotherapy or correction of thyropathies is possible on the basis of morpho-functional studies of the body [32]. The thyroid gland as a holistic biological structure simultaneously functions at three levels of integration into the hierarchical system of the body: cellular-organelle, organ-tissue, systematically-somatic [33,34]. Given that the basic level of any tissue organization is its cell, and correct analysis and interpretation of cells' morphological studies is only possible with their function, we proposed an innovative approach to the study of thyroid function, based on morpho-functional features of follicular thyrocytes under various influences.

The application of electron microscopy permits to study in detail the ultrastructural organization of cells and the dynamics of their cytoplasmic structures' rearrangement both in normal and pathological conditions, and under the influence of various factors (drugs, biologically active substances, poisons, pollutants). Until recently, the study of the ultraarchitectonics of thyroid cells was carried out mainly descriptively using the words of the language used. At the same time, this method of analysis has a number of significant shortcomings, the main of which is the significant subjectivity in assessing changes in the ultrastructural picture and the impossibility of further transformations of the data obtained. The use of computer software, by means of which one can determine the area and percentage of certain structural components in the cell hyaloplasm, despite the ability to describe the state of the cell with numbers, did not solve the problem. The main disadvantage of such software is the inability to fully objectify the degree and direction of structural and functional changes. Taken together, this prompted us to develop a method of studying follicular thyrocytes, which permits to take into account qualitative and binary information about their morphofunctional features in a wide range.

Ultrathin $(4-6 \mu \mathrm{m})$ sections of the studied hormonal tissue made according to routine methods of electron microscopic examination are to be studied. After a visual 
inspection of the histological picture in-depth study begins with electronogram. Our combination of traditional and modern mathematical methods is innovative.

The morpho-functional state of cells is studied by the method of semiquantitative analysis of electronograms [35], which is carried out according to a certain algorithm [36]. At the beginning of the study, we apply the principle of the phase interval method [37], the essence of which is to compare the actual state of cell ultrastructures with the state of similar ultrastructures in two diametrically opposed controls, which are the norm (control 1) and the studied untreated pathology (control 2). The number and features of structure of ultrastructures, a condition of electronic density of lysosomes, mitochondria, secretory granules, cytoplasm, intrafollicular colloid are subject to analysis. Based on the principle of Fuzzy logic [38], the number and state of all considered ultrastructures are ranked within "little - moderate much". To transform these qualitative and binary data into quantitative indices, they are assigned the appropriate symbol; then a digital assessment is carried out according to the degree of symptoms' manifestation. Quantitative assessment of each symptom's manifestations degree is carried out using a scale in the range of $0-4$ points. Absence of a sign is estimated as 0 points, insignificant displays - in 1 point, moderate displays - in 2 points, considerable displays - in 3 points; the maximum value accounts to a score of 4 points. Numerical assessment parameters can also be specified as a percentage [29]. Quantitative information about the state of the cell in accordance with the requirements of mathematical statistics is averaged to determine the arithmetic mean and its standard error $(\mathrm{M} \pm \mathrm{m})$. The obtained numerical indices can be used as primary material for creating databases or for further mathematical transformations in in-depth study, most frequently - for correlation analysis to determine the relationships and interdependencies between ultrastructural components of the studied directions of follicular thyrocytes' activity. Special (synthetic, secretory, transport, energy) capabilities of the cell are studied by method on specifying the profiles of special capabilities of hormone-poietic cells [35]. If a certain direction of the hormoneproducing cell is marked as a capability, its consequence will be the creation of profiles of relevant capabilities, the implementation of which is provided by certain 

ultrastructural elements [39]. In this case, the activity of the hormone-producing cell can be represented as occurring in four directions: 1) hormone synthesis; 2) hormone secretion; 3) hormone transport by intraorgan capillary bed; 4) energy supply of these processes. The implementation of each field of activity is carried out by specialized organelles. As a cybernetic structure, the cell has different clusters of organelles - sets of functionally determined ultrastructures. We refer to such functional cell clusters as "capability profiles". To ensure reliable cell activity, the profiles of capabilities are mainly multicomponent, i.e., they consist of several ultrastructures, the functions of which are interconnected and complementary [33]. According to Mintser et al. (2021), biological objects are able to create their own norms and constantly harmonize their capabilities to ensure the stability of functioning; in this case, the formalization of biological concepts about the existence of stable states is extremely necessary [40]. In this aspect, we pay attention to the topographic interposition of ultrastructures in the cluster, which provides better performance of the functional task. Based on the positions of cytophysiology, we believe that [39]:

- the synthetic capability profile of the hormone-producing cell is represented by the rough endoplasmic reticulum, the Golgi apparatus, free ribosomes located in the cytoplasm and bound ribosomes located on the substructures of the rough endoplasmic reticulum; electron density of the cytoplasm reflects the intensity of synthetic processes occurring in the cell;

- the secretory capability profile is represented by lysosomes and secretory granules; in thyroid follicular thyrocytes, microvilli of their apical surfaces and the electron density of the intrafollicular colloid are added to this list;

- the transport capability profile is characterized by pericapillary space, endotheliocytes of the microcapillary bed, basal membranes of follicular thyrocytes;

- the energy capability profile - mitochondria.

An informative and promising approach to studying the peculiarities of cell functioning in different conditions is the analysis and interpretation of data obtained by correlation analysis [41]. Using the well-known Pearson's formula (1) with 
subsequent interpretation of the results obtained of linear correlation by the Chaddock scale [42], we establish the strength and direction of the traced correlations.

$$
r_{x y}=\frac{\sum_{i=1}^{i=n}\left(x_{i}-\bar{x}\right)\left(y_{i}-\bar{y}\right)}{\sqrt{\sum_{i=1}^{i=n}\left(x_{i}-\bar{x}\right)^{2} \sum_{i=1}^{i=n}\left(y_{i}-\bar{y}\right)^{2}}}
$$

where $\boldsymbol{r}_{x y}$ - coefficient of pair correlation between the indices $x$ and $y ; \boldsymbol{x}_{i}$ - the $x$ index value in $i$-observation; $\boldsymbol{y}_{\boldsymbol{i}}$ - the $y$ index value in $i$-observation; $\boldsymbol{n}$ - number of observations, $\bar{x}$ - mean value of the $x$ index for $n$ observations performed; $\bar{y}$ - mean value of the $y$ index for $n$ observations performed.

The most significant straight lines are considered to be very high $\left(1.00 \geq \mathrm{r}_{x y}\right.$ $\geq 0.91)$ and high $\left(0.90 \geq r_{x y} \geq 0.71\right)$ connections; in their absence, we study direct salient $\left(0.70 \geq r_{x y} \geq 0.51\right)$ and direct moderate $\left(0.50 \geq r_{x y} \geq 0.31\right)$ connections. At the same time, indirect connections can often confirm the information obtained by analyzing direct connections, and therefore also need to be studied. This approach permits to deeply study the influence of various factors on various aspects of the follicular thyrocyte activity. We achieve this with another innovative technique - designing correlation portraits of capability profiles, which are graphical representations of correlations, which was established between the constituent elements of the profile of one capability (intrasystem correlation portrait) or between elements of profiles of different capabilities (intersystem correlation portrait).

The analysis of information obtained with the help of correlation portraits is also carried out based on interpretation of cytophysiological data on the functional role of each organelle that is part of the studied profile cluster [43-45]. The generalized characteristic of the portrait as an integral structure is established by its approach/distance to the norm/pathology. As examples, we give intrasystem correlation portraits of the energy capability profile of follicular thyrocytes in the conditions of norm, hypo- and hyperthyroidism with interpretation of the obtained results. Correlation portraits of synthetic, secretory and transport capabilities profiles 
of follicular thyrocytes of white male rats, studied in similar conditions, were published in our previous works [46-48].

The following characteristics of mitochondria were used to study the features of the relationships between the constituent elements of the energy capabilities cluster of follicular thyrocytes: the number of mitochondria; form of mitochondria; condition of mitochondrial matrix (presence/absence of granularty); electron density of mitochondrial matrix; the presence of ribosomes on mitochondrial cristae; presence/absence of degenerative changes (swelling of mitochondrial cristae, change in the configuration of mitochondrial cristae, change in the structure of mitochondrial cristae, violation of the mitochondrial membrane); presence/absence of mitochondria topographic link with other functionally significant thyrocyte ultrastructures (rough endoplasmic reticulum, Golgi apparatus).

In designing a correlation portrait of the energy capability profile in the intact group 1 rats (Fig. 1), the following connections were traced: very high $(1.00 \geq|\mathrm{r}| \geq$ $0.90)-12$ (4 of which are indirect); salient $(0.70 \geq|\mathrm{r}| \geq 0.51)-26$ (of which 20 are indirect); the analysis of the portrait was carried out based on the established very high connections. The shape of the mitochondria was round (N4) or ovoid (N5), which is shown by a very high connection, established between them. An important sign that the energy processes in thyrocytes take place at a sufficiently high level, we should take into consideration very high connections between mitochondria of medium size (N9) and the presence of their topographic relationship with the the rough endoplasmic reticulum and the Golgi apparatus (N12), absence of degenerative changes in mitochondria (N13), distinct shape delineation of mitochondrial cristae (N16).

Such features of thyrocytes' cytophysiology may indicate the presence of conditions optimal for the energy supply of hormonopoiesis. Indirectly, this conclusion can be confirmed by indirect connections of the same strength between homogeneous structure of mitochondrial matrix (N21) and distinct shape delineation of mitochondrial cristae (N16), absence of degenerative changes in mitochondria (N13), mitochondria of medium size (N9), presence of topographic link of mitochondria with the rough endoplasmic reticulum and the Golgi apparatus (N12). 


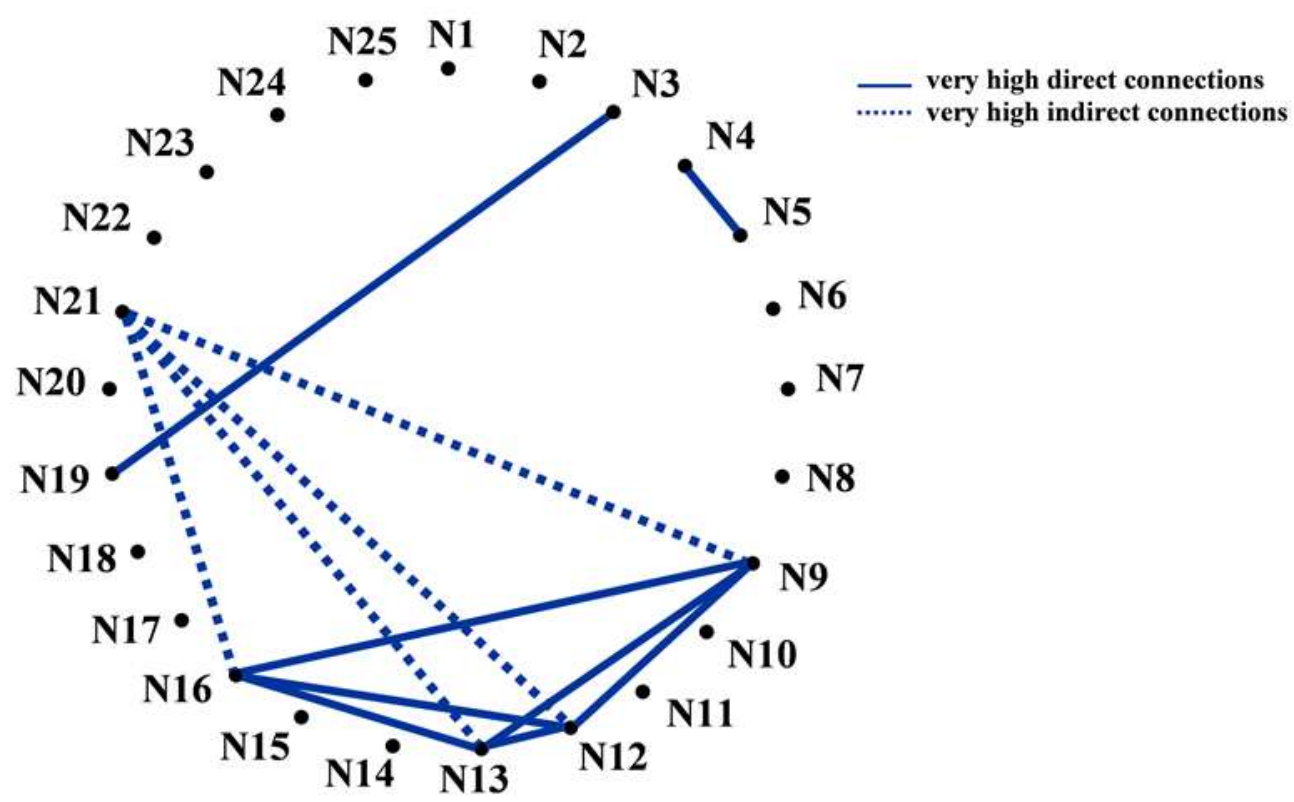

Fig. 1. Correlation portrait of the energy capability profile of follicular thyrocytes in intact white male rats.

In the correlation portrait of group 2 rats, which were kept in conditions of alimentary iodine deficiency (Fig. 2), the following connections were established: very high (1.00 $\geq|\mathrm{r}| \geq 0.91)$ - 18 (of which 10 indirect), salient $(0.70 \geq|\mathrm{r}| \geq 0.51)$ - 29 (of which 18 indirect); the analysis of the portrait was carried out with very high connections taken into account. The architectonics of the portrait in question is characterized by a quantitative advantage of indirect connections, which reduces the stability of the structure. The presence of a very high direct connection between mitochondria with round (N4) and ovoid (N5) forms suggests that in iodine deficiency such a connection is important to maintain thyrocyte energy supply processes at a sufficient level.

The established above can confirm the preliminary conclusion about the importance of mitochondria shape for cell energy supply: in the discussed conditions of alimentary iodine deficiency in rounded (N4) and ovoid (N5) shapes of mitochondria it is impossible to provide their moderate number (N2), which is an important prerequisite for full energy flow processes in thyrocytes. This is indicated by the very high indirect connections observed between the moderate number of mitochondria (N2), the rounded (N4) and ovoid (N5) shape of mitochondria; and connections of the 
same strength and direction that the granular structure of the mitochondrial matrix (N22) forms with the rounded (N4) and ovoid (N5) shape of the mitochondria; and, in turn, N4 and N5 - with no degenerative changes in them (N13) and a distinct shape delineation of mitochondrial cristae (N16). This is also confirmed by the indirect connection between big sized mitochondria (N10) with moderate number of ribosomes on mitochondrial crystae (N19). At the same time, very high connections between moderate number of mitochondria (N2), absence of degenerative changes (N13), distinct shape delineation of mitochondrial cristae (N16) and granular structure of mitochondrial matrix (N22) may indicate favorable conditions for intrathyrocytes' cell energy. The preservation of a sufficient level of energy supply for thyrocyte activity in the conditions of alimentary iodine deficiency can also be evidenced by very high connections between the absence of degenerative changes in mitochondria (N13) and distinct shape delineation of mitochondrial cristae (N16); distinct shape delineation of mitochondrial cristae (N16) and granular structure matrix (N22); a moderate number of ribosomes in the mitochondrial matrix (N19) and the existing topographic relationship of mitochondria with the rough endoplasmic reticulum and Golgi apparatus (N12).

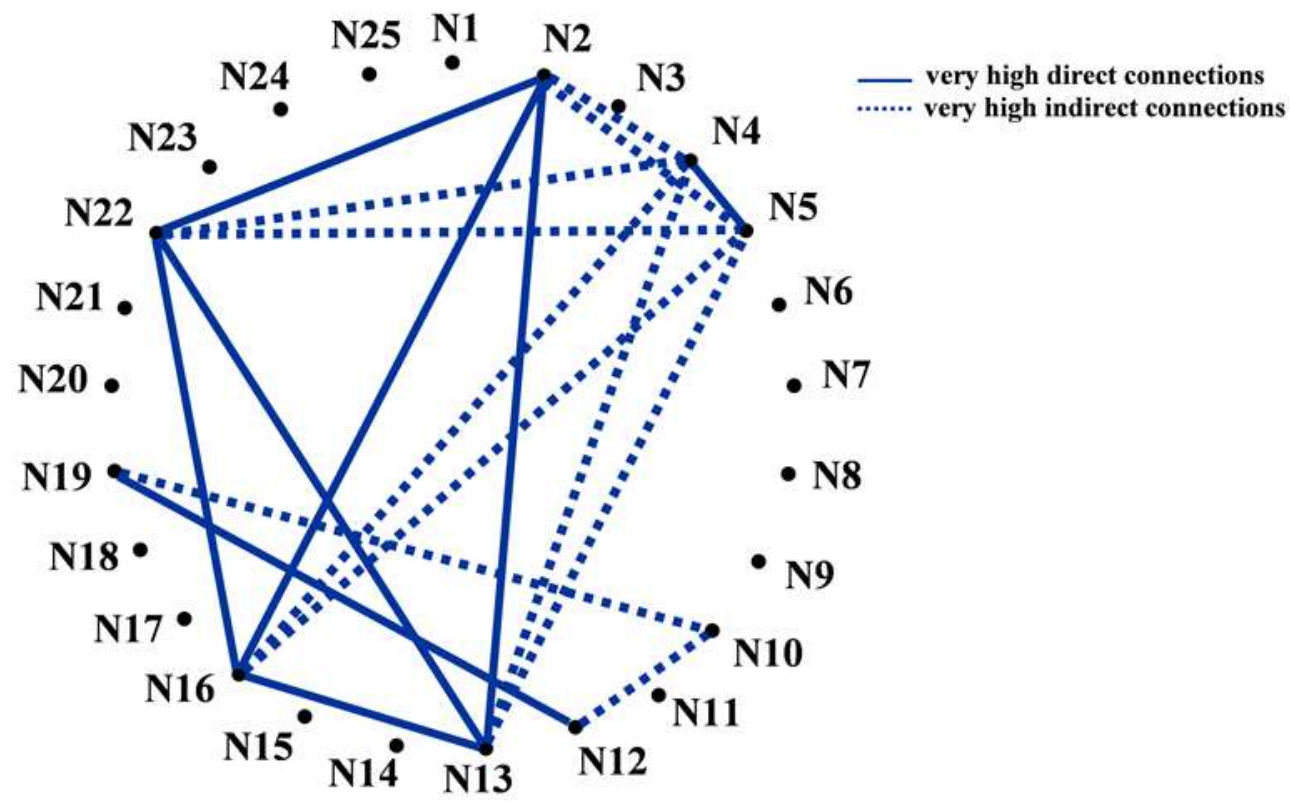

Fig. 2. Correlation portrait of the energy capability profile of follicular thyrocytes in white male rats in the conditions of alimentary iodine deficiency. 
The correlation portrait of group 3 rats, which were kept in conditions of mercazolil-potentiated alimentary iodine deficiency (Fig. 3), is characterized by the following connections: very high $(1.00 \geq|\mathrm{r}|>0.91)-10$ (of which 4 are indirect); high $(0.90 \geq|\mathrm{r}| \geq 0.71)-12$ (of which 6 indirect). Very high connections between mitochondria of round shape (N4) and mitochondria of moderate and significant electron density of matrix (N24 and N25, respectively); and high direct connection between the moderate number of mitochondria (N2) and the absence of degenerative changes in them (N13) suggests that despite the potentiation of alimentary iodine deficiency, thyrocytes have sufficient energy resources. At the same time, a very high connection between the homogeneous structure of the mitochondrial matrix (N21) and the absence of topographic link of mitochondria with the rough endoplasmic reticulum and Golgi apparatus (N11) may be a sign of disturbances in the energy supply system. This assumption can be confirmed by high indirect connections traced between the absence of degenerative changes in mitochondria (N13) and round mitochondria (N4); and also between the granular structure of mitochondrial matrix (N22) and an insignificant, and moderate number of ribosomes on mitochondrial cristae (N18 and N19 respectively).

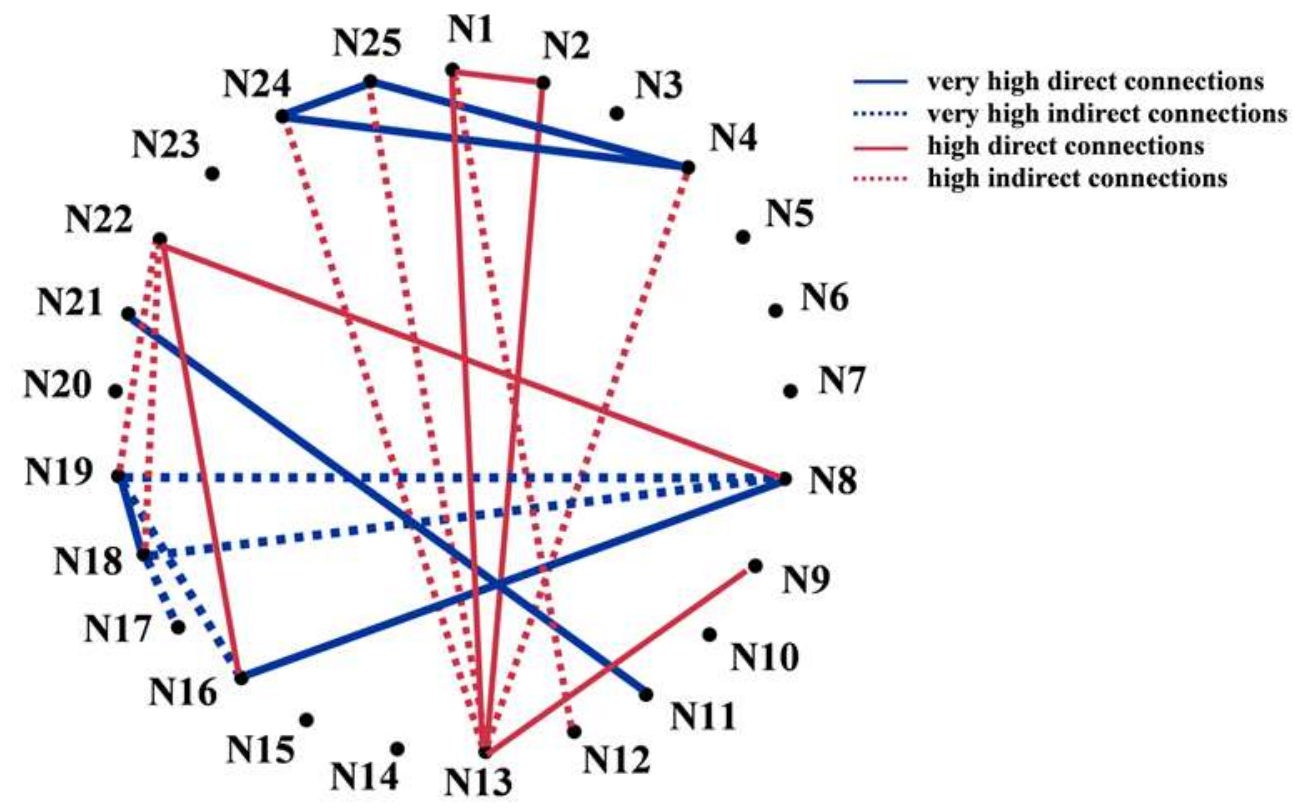

Fig. 3. Correlation portrait of the energy capability profile of follicular thyrocytes in white male rats in the conditions of mercazolil-potentiated $(3 \mathrm{mg} / \mathrm{kg}$ body weight) alimentary iodine deficiency. 
In the conditions of thyreoidinum-induced hyperthyroidism, the correlation portrait of group 4 rats (Fig. 4) had the following connections: very high $(1.00 \geq|r|>$ 0.91) - 9 (of which 6 indirect); high $(0.90 \geq|\mathrm{r}| \geq 0.71)$ - 11 (of which 6 indirect). The architecture of the portrait was characterized by symmetry, which is one of the prerequisites for the realization of the energy potential of thyrocytes. This is also indicated by the high direct connections traced between the round (N4) and ovoid (N5) shape of mitochondria; between the ovoid shape of mitochondria (N5) and the distinct shape delineation of mitochondrial cristae (N16); and the very high direct connection between distinct shape delineation of mitochondrial cristae (N16) and round mitochondria (N4). However, the presence of a high direct connection between ovoid mitochondria (N5) and the blurred shape delineation of mitochondrial cristae (N15) may be a sign of some difficulties in energy supply of specific thyrocyte activity. Significant evidence of this assumption can be found in the very high connections established between the granular structure of mitochondrial matrix (N22) and the absence of topographic link of mitochondria with the rough endoplasmic reticulum and Golgi apparatus (N11); and between a moderate electron density of the mitochondrial matrix (N24) and an insignificant number of mitochondria (N1).

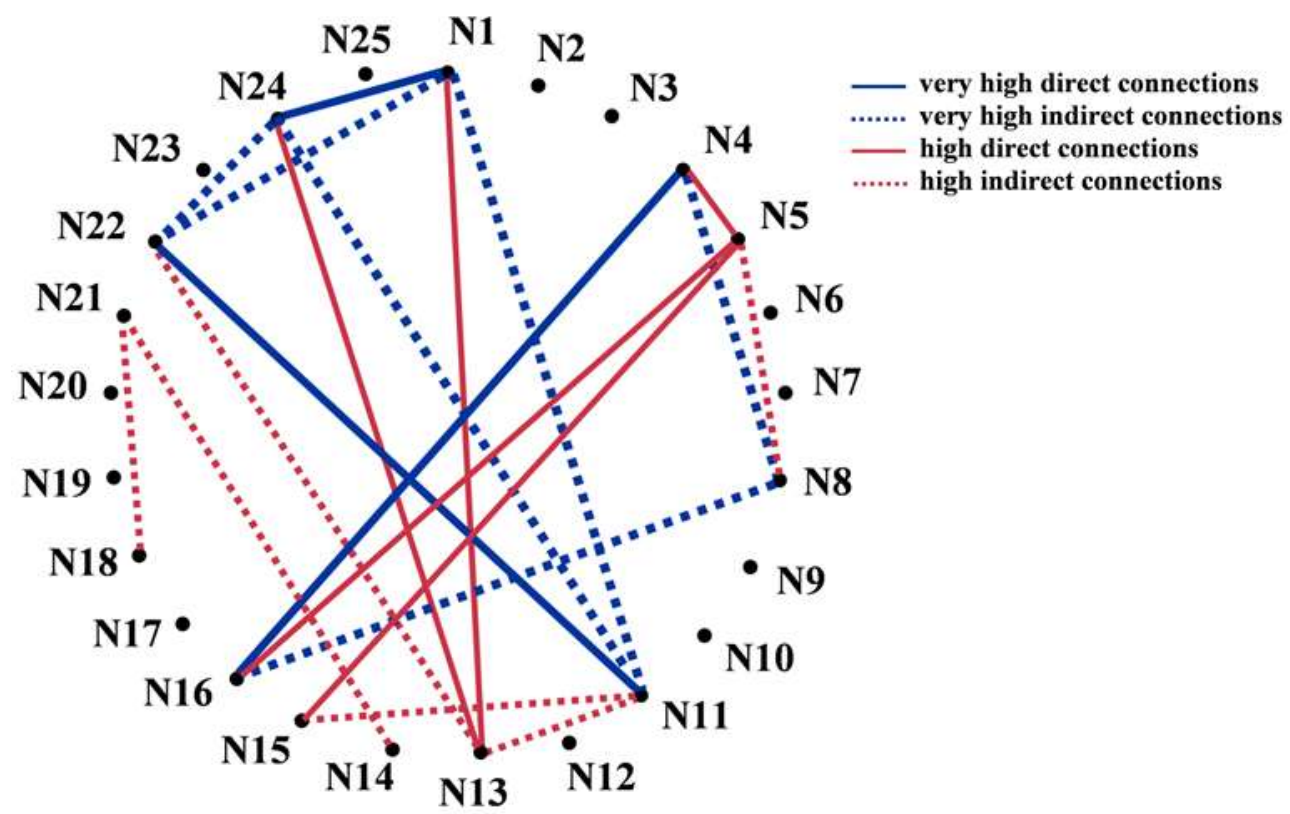

Fig. 4. Correlation portrait of the energy capability profile of follicular thyrocytes in white male rats in the conditions of thyreoidinum-induced $(15 \mathrm{mg} / 100 \mathrm{~g}$ body weight) hyperthyroidism. 
Thus, a mathematical approach to in-depth study of the thyroid gland as an organ that is an important part of the body's regulatory systems and responsible for tissue reproduction, becomes extremely necessary.

\section{Conclusions.}

1. Despite the available information about the defeat of the thyroid gland by SARSCov-2 in COVID-19, scientists have not reached a consensus on the importance of the organ's pathology for the disease or worsening its consequences.

2. The thyroid gland is of great importance for the coordinated activity of all organs and systems of the body, which highlights the problem of in-depth study of various aspects of its activities.

3. The disclosure of the deep essence of the processes that take place in the thyroid gland, goes beyond any single branch of medicine and suggests the integrated use of physiological, morphological, biochemical, clinical and other fields of studies.

4. We developed a multidisciplinary method of studying different directions of hormone-producing cells activity based on the integrated use of mathematical methods for designing correlation portraits, which we tested in the study of follicular thyrocytes, permits to study changes in follicular thyrocytes/thyroid gland as a separate organ and changes in follicular thyrocytes/thyroid gland which may occur indirectly in response to changes in other organs/environment.

Ethical approval. Ethical clearance was obtained from the administration of Lviv Medical Institute LLC. A permission statement for conducting the experiments was received from the administration of Lviv Medical Institute LLC. Before any data collection, the main purpose of the study was clearly explained to each department (concerned personnel).

Funding. The authors state, that there was no funding from any agencies for this study. 


\section{References.}

1. COVID-19 - Coronavirus Pandemic: Coronavirus Statistics. Worldometer. Last updated: January $20, \quad 2022, \quad 12: 36 \quad$ GMT. $\quad$ URL: https://www.worldometers.info/coronavirus/.

2. Hariyanto T.I., Kurniawan A. Thyroid disease is associated with severe coronavirus disease 2019 (COVID-19) infection. Diabetes Metab Syndr. 2020. Vol. 14. Iss. 5. P. 1429-1430. DOI: 10.1016/j.dsx.2020.07.044.

3. Melo G.M., Gonçalves A.J., Walder F. et al. Analysis of the status of treatment of benign thyroid diseases - a public health problem aggravated in the COVID-19 pandemic era. Braz J Otorhinolaryngol. 2021. Article S1808-8694(21)00170-1. DOI: 10.1016/j.bjorl.2021.08.008.

4. Kogan E.A., Berezovsky Yu.S., Protsenko D.D. et al. Pathological anatomy of infection caused by SARS-CoV-2. Russian Journal of Forensic Medicine. 2020. Vol. 6. Iss. 2. P. 8-30. DOI: 10.19048/2411-8729-2020-6-2-8-30.

5. Aguiar D., Lobrinus J. A., Schibler M. et al. Inside the lungs of COVID-19 disease. Int J Legal Med. 2020. Vol. 134. No. 4. P. 1271-1274. DOI: 10.1007/s00414020-02318-9.

6. Pomara C., Volti G. L., Cappello F. COVID-19 Deaths: Are We Sure It Is Pneumonia? Please, Autopsy, Autopsy, Autopsy! J Clin Med. 2020. Vol. 9. No. 5. P. 1259. DOI: $10.3390 / \mathrm{jcm} 9051259$.

7. Su H., Yang M., Wan C., Yi L et al. Renal histopathological analysis of 26 postmortem findings of patients with COVID-19 in China. Kidney Int. 2020. Vol. 98. No. 1. P. 219-227. DOI: 10.1016/j.kint.2020.04.003.

8. Bansal M. Cardiovascular disease and COVID-19. Cardiovascular disease and COVID-19. Diabetes Metab Syndr. 2020. Vol. 14. No. 3. P. 247-250. DOI: 10.1016/j.dsx.2020.03.013.

9. Chen T., Wu D., Chen H. et al. Clinical characteristics of 113 deceased patients with coronavirus disease 2019: retrospectivestudy. BMJ. 2020. Vol. 368. Article m1295. DOI: 10.1136/bmj.m1295. 
10. Feghali K., Atallah J., Norman C. Manifestations of thyroid disease post COVID-19 illness: Report of Hashimoto thyroiditis, Graves' disease, and subacute thyroiditis. Clin Transl Endocrinol Case Rep. 2021. Vol. 22. Article 100094. DOI: 10.1016/j.jecr.2021.100094.

11. Scappaticcio L., Pitoia F., Esposito K. et al. Impact of COVID-19 on the thyroid gland: an update. Rev Endocr Metab Disord. 2020. Vol. 22. No 4. P. 803-815. DOI: 10.1007/s11154-020-09615-z.

12. Franceschi C., Ostan R., Mariotti S. et al. The agingthyroid: A reappraisal within the geroscience integrated perspective. Endocr Rev. 2019. Vol. 40. No 5. P. 12501270. DOI: 10.1210/er.2018-00170.

13. Bao R., Hernandez K., Huang L., Luke J.J. ACE2 and TMPRSS2 expression by clinical, HLA, immune, and microbial correlates across 34 human cancers and matched normal tissues: implications for SARS-CoV-2 COVID-19. J Immunother Cancer. 2020. Vol. 8. No 2. Article e001020. DOI: 10.1136/jitc-2020-001020.

14. Li M.Y., Li L., Zhang Y. et al. Expression of the SARS-CoV-2 cell receptor gene ACE2 in a wide variety of human tissues. Infect Dis Poverty. 2020. Vol. 9. No 1. Article 45. DOI: 10.1186/s40249-020-00662-x.

15. Murugan A.K., Alzahrani A.S. SARS-CoV-2: Emerging role in the pathogenesis of various thyroid diseases. J Inflamm Res. 2021. No 14. P. 6191-6221. DOI: 10.2147/JIR.S332705.

16. Ryabukha O.I. Body weight as an indicator of the organism's general condition while receiving iodine of organic and inorganic chemical origin under conditions of the optimal iodine supplementing. Bulletin of problems in biology and medicine. 2018. Iss. 1. No 1(142). P. 97-102. DOI: 10.29254/2077-4214-2018-1-1-142-97-102.

17. Ryabukha O., Dronyuk I. Applying regression analysis to study the interdependence of thyroid, adrenal glands, liver, and body weight in hypothyroidism and hyperthyroidism. CEUR Workshop Proceedings-Series. 2019. Vol. 2488. P. 155164. URL: http://ceur-ws.org/Vol-2488/paper13.PDF.

18. Ryabukha $\mathrm{O}$, Greguš $\mathrm{ml} \mathrm{M}$. Correlation analysis as a thyroid gland, adrenal glands, and liver relationship tool for correcting hypothyroidism with organic and 
inorganic iodine. Procedia Comput Sci. 2019. Vol. 160. P. 598-603. DOI: 10.1016/j.procs.2019.11.041.

19. Koubassov R.V. Hormonal changes in response to extreme environment factor. Annals of the Russian Academy of Medical Sciences. 2014. Vol. 69. No. 9-10. P. 102109. URL: https://vestnikramn.spr-journal.ru/jour/article/view/395/335.

20. Ryabukha O.I., Fedorenko V.I. Environmental determinants of thyroid pathology. Medicni perspectivi. 2021. Vol. 26. No. 3. P. 169-178. DOI: 10.26641/2307-0404.2021.3.242253

21. Menon K., Skeaff S. Iodine: Iodine Deficiency Disorders (IDD). In: B. Caballero, P.M. Finglas, F. Toldrá (ed.). Encyclopedia of Food and Health. New York: Academic Press; 2016. p.p. 437-443. DOI: https://doi.org/10.1016/B978-0-12384947-2.00399-8.

22. Aburto N., Abudou M., Candeias V., Wu T. Effect and safety of salt iodization to prevent iodine deficiency disorders: a systematic review with meta-analyses. WHO eLibrary of Evidence for Nutrition Actions (eLENA). Geneva: World Health Organization; 2014. URL: https://www.who.int/publications/i/item/9789241508285.

23. Santos J.A.R., Christoforou A., Trieu K. et al. Iodine fortification of foods and condiments, other than salt, for preventing iodine deficiency disorders. Cochrane Database Syst Rev. 2019. Vol. 2. No 2. Article CD010734. DOI: 10.1002/14651858.CD010734.pub2.

24. Korzun V.N., Vorontsova T.O., Antoniuk I.Yu. Study of the Black Sea algae influence on thyroid function and prevention of iodine deficiency. In: V.N. Korzun (ed.). Ecology and diseases of thyroid gland. Kyiv: Medinform; 2018. p.p. 607-622. 25. Kravchenko V.M., Orlova V.O., Laryanovska Yu.B., Sakharova T.S. Investigation of Laminaria aqueous extract effect on thyroid gland morphological status in rats with experimental hypothyroidism induced by sodium perchlorate. Ukrayinskyy biofarmatsevtychnyy zhurnal. 2017. No. 6. P. 50-55. DOI: https://doi.org/10.24959/ubphj.17.144. 
26. Gazha P.A, Andrianov A.M, Stepaniuk I.A et al. Isolation of iodine-protein components from sea algae. Prikl Biokhim Mikrobiol. 1976. Vol. 12. No. 4. P. $597-$ 601. URL: https://www.ncbi.nlm.nih.gov/pubmed/1026942.

27. Ryabukha O.I. To the problem of application in hypothyrosis inorganic and organic iodine (review). Actual problems of transport medicine. 2018. No. 2. P. 7-21. DOI: $10.5281 /$ zenodo.1319531.

28. Tiwari M. A mathematical applications into the cells. J Nat Sci Biol Med. 2012. Vol. 3. No. 1. P. 19-23. DOI: 10.4103/0976-9668.95937.

29. Riabukha O. Application of new information technologies for the study of cell activity. In: Proceedings of the XIth International Conference on Perspective Technologies and Methods in MEMS Design (MEMSTECH); 2015 Sep 2-6; Lviv, Ukraine. New York (NY), United States: IEEE; 2015. P. 69-71. URL: http://ieeexplore.ieee.org/document/7299458.

30. Ryabukha O.I, Dronyuk I.M. Application of correlation analysis in cytology: Opportunities to study specific activity of follicular thyrocytes. Regulatory Mechanisms in Biosystems. 2019. Vol. 10. No 3. P. 345-351. DOI: 10.15421/021953. 31. Zadeh L. A. The roles of fuzzy logic and soft computing in the conception, design and deployment of intelligent systems. BT Technology Journal. 1994. Vol. 14. No 4. P. 32-36. DOI: 10.1109/FUZZY.1997.616336.

32. Avtandilov G. G. Basis of quantitative pathological anatomy. Moscow: Meditsina; 2002.

33. Avtandilov G.G.: Medical morphometry: A guide. Moscow: Meditsina; 1990.

34. Ryabukha O.I. Conceptual approaches to the study of the thyroid gland at different levels of its integration into the body. Endocrinology and Disorders. 2020. Vol. 4. Iss.1. DOI: 10.31579/2640-1045/047.

35. Ryabukha O.I. Perspectives of applying new approaches to the implementation of mathematical technologies in the study of cell activity. Medical Informatics and Engineering. 2018. No. 1. P. 67-75. DOI: 10.11603/mie.1996-1960.2018.1.8894. 
36. Ryabukha O., Dronyuk I. The portraits creating method by correlation analysis of hormone-producing cells data. CEUR Workshop Proceedings-Series. 2018. Vol. 2255. P. 135-145. URL: http://ceur-ws.org/Vol-2255/paper13.pdf.

37. Plashchevaya E.V., Smirnov V.A., Nigei N.V., Lysak V.A. The main types of medical logic. In: Textbook for practical training in medical informatics. Blagoveshchensk: Amur State Medical Academy, 2014. p. 176.

38. Dev U., Sultana A., Saha D., Mitra N. Application of Fuzzy logic in medical data interpretation. Bangladesh Journal of Scientific and Industrial Research. 2015. Vol. 49. No. 3. P. 137-146. DOI: 10.3329/bjsir.v49i3.22127.

39. Ryabukha O. Innovative model for studying the features of hormono-poietic cells functioning based on characteristics of different aspects in their activity (as examplified by follicular thyrocytes). In: Scientific basis of modern medicine: collective monograph. Boston: Primedia eLaunch, 2020. pp. 171-181. DOI: 10.46299/isg.2020.MONO.MED.I.

40. Mintser O.P., Karlenko V.P., Shevchenko Ya.O., Sukhanova O.O. Clusterization of functional states of the organism. Pilot study. Medical Informatics and Engineering. 2021. No. 2. P. 4-13. DOI: 10.11603/mie.1996-1960.2021.2.12449. 41. Uurtio V., Monteiro J.M., Kandola J. et al. A Tutorial on Canonical Correlation Methods. ACM Computing Surveys. 2018. Vol. 50. No. 6. Article 95. DOI: $10.1145 / 3136624$.

42. Koterov A.N., Ushenkova L.N., Zubenkova E.S. et al. Strength of association. Report 2. Graduations of Correlation Size. Medical Radiology and Radiation Safety. 2019. Vol. 64. No. 6. P. 12-24. DOI: 10.12737/1024-6177-2019-64-6-12-24.

43. Caplan M.J. Functional organization of the cell. In: W. F. Boron, E. L. Boulpaep (Eds.). Medical Physiology, 3rd ed. Philadelphia: Elsevier; 2016. pp. 8-46.

44. Giorgi C., De Stefani D., Bononi A. et al. Structural and functional link between the mitochondrial network and the endoplasmic reticulum. Int J Biochem Cell Biol. 2009. Vol. 41. No. 10. P. 1817-1827. DOI:10.1016/j.biocel.2009.04.010.

45. Kirsten D. The thyroid gland: physiology and pathophysiology. Neonatal Netw. 2000. Vol. 19, No 8. P. 11-26. DOI: 10.1891/0730-0832.19.8.11. 
46. Ryabukha O.I. Search for markers of changes of the synthetic activity of thyrocyte under the influence of iodine reception in iodine deficiency conditions. World of Medicine and Biology. 2018. No. 3. P. 179-185. DOI: 10.26724/2079-83342018-3-65-179-185.

47. Ryabukha O.I. Application of mathematical approaches in medicine on the example of follicular thyrocytes secretory activity study. World of Medicine and Biology. 2019. No 1. P. 181-187. DOI: 10.26724/2079-8334-2019-1-67-181.

48. Ryabukha O., Dronyuk I. Modern approaches to the applying of mathematical methods in the analysis of the transport direction of follicular thyrocytes. CEUR Workshop Proceedings-Series. 2021. Vol. 3038. P. 302-316. URL: http://ceurws.org/Vol-3038/paper19.pdf. 